HISTORIA: Jurnal Pendidik dan Peneliti Sejarah, 5(1), 81-88. https://doi.org/10.17509/historia.v5i1.34537

Available online at HISTORIA; Jurnal Pendidik dan Peneliti Sejarah
Journal homepage: https://ejournal.upi.edu/index.php/historia

\title{
PERANAN ULAMA MUHAMMADIYAH DALAM PEMBENTUKAN APS (ASKAR PERANG SABIL) DI YOGYAKARTA TAHUN 1947-1949
}

\author{
Siti Nurul Hidayah, Muhammad Iqbal Birsyada \\ Program Pendidikan Sejarah Universitas PGRI Yogyakarta \\ Correspondence: iqbal@upy.ac.id
}

\begin{abstract}
To cite this article: Hidayah, S.N., \& Birsyada, M.I. (2022). Peranan ulama muhammadiyah dalam pembentukan aps (askar perang sabil) di yogyakarta tahun 1947-1949. HISTORIA: Jurnal Pendidik dan Peneliti Sejarah, 5(1), 81-88. https://doi. org/10.17509/historia.v5i1.34537.
\end{abstract}

Naskah diterima : 28 Mei 2021, Naskah direvisi : 20 Februari September 2021, Naskah disetujui : 20 Desember 2021

\begin{abstract}
Purpose of this research is to find out: (1) What is the general picture of Yogyakarta during the Physical Revolution in Indonesia (2) What is the General Picture of Ulama during the Physical Revolution in Yogyakarta (3) How the Role of Muhammadiyah Ulama in the Formation of APS (Askar War Sabil) in Yogyakarta. The method used in this research is Literature with five stages, namely: (1) Selection of topics, determining the main points of the problem to be studied, (2) Heuristics, (3) Criticizing sources, (4) interpretation, analyzing sources that have been tested for their validity, (5) histiography, chronological historical arrangement so that historical writing is compiled. The results of this study indicate (1) the Physical Revolution in Yogyakarta occurred due to several things, namely, the Dutch Military Aggression I, the PKI Rebellion in Gunungkidul, the Dutch Military Aggression II and the March 1 General Offensive, (2) During the Physical Revolution in Yogyakarta, scholars such as NU, MIAI have a role in fighting for independence, one of which is in establishing Islamic warriors such as Hisbullah and Sabilillah (3) the ulama in Yogyakarta, namely Muhammadiyah also participated in the Physical Revolution, namely in the formation of APS and in providing Physical, Idiological and Physical exercises. Spirituality.
\end{abstract}

Keywords: Askar Sabil War; Muhammadiyah: Physical Revolution.

\begin{abstract}
Abstrak
Tujuan penelitian ini adalah untuk mengetahui: (1) Bagaimana Gambaran umum Yogyakarta Pada Masa Revolusi Fisik di Indonesia (2) Bagaimana Gambaran Umum Ulama Masa Revolusi Fisik di Yogyakarta (3) Bagaimana Peranan Ulama Muhammadiyah dalam Pembentukan APS (Askar Perang Sabil) di Yogyakarta. Metode yang digunakan dalam penelitian ini adalah Literatur dengan lima tahapan, yakni: (1) Pemilihan topik, menentukan pokok-pokok masalah yang akan diteliti, (2) Heuristik, (3) Kritik sumber, (5) Historiografi, penyusunan sejarah secara kronologis sehingga tersusunlah penulisan sejarah. Hasil penelitian ini menunjukkan (1) Revolusi Fisik di Yogyakarta terjadi karena beberapa hal yaitu, Agresi Militer Belanda I, Pemberontakan PKI di Gunungkidul, Agresi Militer Belanda II dan Serangan Umum 1 Maret, (2) Pada masa Revolusi Fisik di Yogyakarta, Para ulama seperti NU, MIAI memiliki peranan dalam memperjuangkan kemerdekaan salah satunya yaitu dalam mendirikan laskar-laskar islam seperti Hisbullah dan Sabilillah (3) para ulama di Yogyakarta yaitu Muhammadiyah juga ikut berpartisipasi pada masa Revolusi Fisik yaitu dalam pembentukan APS dan dalam memberikan latihan-latihan Fisik, Idiologi dan Kerohanian.
\end{abstract}

Kata kunci: Askar Perang Sabil; Revolusi Fisik; Ulama Muhammadiyah.

HISTORIA: Jurnal Pendidik dan Peneliti Sejarah, p-issn:2620-4789 | e-issn:2615-7993 


\section{PENDAHULUAN}

Proklamasi Kemerdekaan Indonesia pada tanggal 17 Agustus 1945 yang diproklamasikan oleh Presiden Sukarno dan Wakil Presiden Mohammad Hatta di Jalan Pegangsaan Timur No.56 Jakarta pada pukul 10.00 WIB (Pidada, 2018) merupakan titik awal berdirinya negara Indonesia yang merdeka dan berdaulat dan butuh waktu yang sangat panjang bagi Bangsa Indonesia untuk memperoleh suatu kemerdekaan. Setelah Proklamasi kemerdekaan, Indonesia masih belum sepenuhnya dapat di rasakan oleh rakyat Indonesia. Hal ini dikarenakan Belanda kembali datang ke Indonesia. Selama masa penjajahan itu, mereka bersamasama ikut melakukan pemberontakan serta perlawanan. Masa setelah kemerdekaan ini dikenal sebagai masa Revolusi Fisik (Susilo, 2018).

Situasi yang terjadi di Indonesia pada masa Revolusi Fisik telah membuat bangsa indonesia sangat menderita. Penderitaan ini tidak lain disebabkan oleh penjajahan Belanda yang berlangsung kuranglebih tiga setengah abad lamanya dan kemudian dilanjutkan dengan penjajahan Jepang yang hanya sebentar namun amat kejam. Rasa sakit yang diderita oleh rakyat karena penjajahan ini membuat rakyat bersama-sama mewujudkan rasa persatuan dengan bangkit untuk mempertahankan kemerdekaan Indonesia. wujud dari rasa persatuan rakyat Indoensia ini dengan dikibarkannya Bendera Sang Saka Merah Putih harus dikibarkan di seluruh wilayah Indonesia (Tashadi, Suratmin, Mulyono, dkk, 1991).

Secara sosial kedatangan Belanda ke Inodonesia ini tentu saja mendapatkan tanggapan yang tidak baik dari pihak Indonesia, sehingga pada tanggal 21 Juli 1947 Belanda melancarkan agresi militer ke Indonesia pada malam hari. Serangan yang dilakukan oleh tentara Belanda berfokuskan pada tiga tempat, yaitu Sumatra Timur, Jawa Tengah, dan Jawa Timur sedangkan di daerah di Sumatra Timur sasaran utamanya adalah daerah perkebunan tebu dan pabrik gula. Yogyakarta yang pada saat itu sebagai pusat pemerintahan juga tak luput dari sasaran agresi militer Belanda. Belanda berdalih bahwa penyerangan yang dilakukannya hanya sekadar tindakan keamanan dan ketertiban setelah terjadinya Agresi Militer Belanda I (Aprianto \& Yulianto, 2019).

Selain aksi yang dilakukan oleh pihak Belanda, ancaman lain yang datang dari Negri Indonesia sendiri yaitu pemberontakan PKI di Madiun. PKI kembali membangkitkan organisasi bersama pimpinan mereka yaitu Amir Syarifuddin. PKI serta kader-kadernya memilih menjadikan Gunungkidul sebagai basis utama kekuatan mereka di Daerah Istimewa Yogyakarta
(Estu Dwiyono, 2012: 67). Setelah pemberontakan PKI berakhir, Belanda yang masih ingin menduduki Indonesia melakukan Agresi Militer Belanda II yang berpusat di daerah Istimewa Yogyakarta. Namun setelah aksi ini terhenti pihak Indonesia merencanakan sebuah penyerangan yang diberi nama serangan Umum 1 Maret, tujuan dari serangan ini yaitu untuk menunjukkan kepada pihak internasional bahwa Indonesia masih ada dan akan segera merdeka (Margana, Ibrahim, \& Nigrum, 2019).

Masa Revolusi Fisik di Indonesia khususnya di Yogyakarta telah membuat seluruh masyarakat berjuang bersama memperjuangkan kemerdekaan bersama para ulama NU, MIAI dan khususnya ulama Muhammadiyah di kancah terdepan maupun di belakang. ulama menduduki posisi penting dalam masyarakat Islam. Ulama tidak hanya dikenal sebagai figur yang hanya memahami ajaran agama tetapi juga ulama juga dapat menjadi figur pengerak dan motivator bagi masyarakat. Ulama merupakan seseorang yang selalu di pandang baik dan menjadi panutan dan teladan oleh masyarakat, sehingga ucapan ulama selalu menjadi pegangan oleh masyarakatnya (Hanafi \& Sofiandi, 2018). Periode ini merupakan suatu masa dimana bangsa Indonesia berjuang untuk melepas diri dari penjajah asing (Diniyanti, 2020).

Secara historis Muhammadiyah merupakan suatu organisasi yang didirikan oleh K.H. Ahmad Dahlan di Yogyakarta pada tanggal 18 November 1912. Faktor yang mendorong terbentukanya organisasi Muhammadiyah di Yogyakarta menurut K.H. Ahmad Dahlan adalah karena keterbelakangan serta kebodohan umat Islam tentang kemiskinan serta kehidupan masyarakat pada saat penjajahan berlangsung di Indonesia (Nur Aini Setiawan, 2018: 110). Apabila dilihat secara kultural Islam yang berkembang di Jawa pada awal mulanya lebih bercorak sintesa dengan budaya lokal daripada corak Islam yang berkembang di wilayah pesisiran. Yogyakarta tempat berdirinya Muhammadiyah masuk wilayah Jawa bagian selatan yang secara kultural adalah pusat kebudayaan Jawa (Maftukhin, 2016). Sintesa corak Islam dan budaya Jawa tidak hanya dipraktekkan dalam kehidupan sehari-hari masyarakat Yogyakarta saja melainkan tradisi dan upacara-upacara yang diselenggarakan oleh kraton banyak yang mencerminkan nuansa mistisme (Woodward, 1989). Singkatnya Yogyakarta telah lama menjadi salah satu kota budaya yang memiliki nikai karakter nilai-nilai Kejawaan yang telah lama melekat pada atribut kultural masyarakat (Birsyada \& Syahruzah, 2018) Melihat situasi kondisi yang seperti inilah Muhammadiyah pada fase awal berusaha untuk 
mengembalikan ajaran dan nilai Islam sebagaimana aslinya bersandar pada Qur'an dan Sunnah.

Setelah terbentuknya organisasi Muhammadiyah ini K.H. Ahmad Dahlan membuka sebuah Madrasah Ibtida'iyah Diniyah Islamiyah pada tanggal 1 Desember 1911 yang bertempatan di rumah K.H. Ahmad Dahlan. Selain itu Muhammadiyah merupakan salah satu organisasi Islam terbesar di Indonesia yang memiliki peran sangat penting dalam dakwah, sosial dan pendidikan (Sutarto, Sari, \& Anrial, 2020). Selain dalam hal pendidikan Muhammadiyah dalam praktik sosial turut andil dalam mengembangkan ekonomi masyarakat (Nakamura\& Mitsuo, 2017).

Salah satu bentuk kecemasan para ulama Muhammadiyah akan datangnya Belanda di Yogyakarta maka para ulama Muhammadiyah sepakat untuk membuat sebuah laskar yang di beri nama APS (Askar Perang Sabil) serta wadah organisasi MUAPS (Markas Ulama Askar Perang Sabil Askar Perang Sabil) yang menampung para Ulama. ASP (Askar Perang Sabil) yang lahir di pertengahan masa Revolusi Fisik di Yogyakarta merupakan Laskar yang turut aktif dalam mempertahankan kemerdekaan indonesia di Yogyakarta. Pembentukan APS (Askar Perang Sabil) ini telah di setujui oleh Sri Sultan Hamengkubuwono IX, persetujuan pembentukan Laskar APS (Askar Perang Sabil) telah tertuang dalam Surat Kekancingan menggunakan bahasa Jawa (Aprianto \& Yulianto, 2019).

Berdasarkan uraian tersebut, peneliti merumuskan beberapa permasalahan, yaitu gambaran umum Yogyakarta pada masa Revolusi Fisik di Indonesia, gambaran umum ulama masa Revolusi Fisik di Yogyakarta serta peranan ulama Muhammadiyah dalam pembentukan APS (Askar Perang Sabil di Yogyakarta).

\section{METODE}

Penelitian ini menggunakan metode penelitian sejarah yang meliputi heuristik, kritik internal dan eksternal, interpretasi, dan historiografi. Pada tahap heuristik atau pengumpulan data, peneliti terlebih dahulu menentukan topik yang akan dibahas (Wasino, 2007). Pemilihan topik dan pokok kajian yang akan diteliti, yaitu Peranan Ulama Muhammadiyah dalam Pembentukan APS (Askar Perang Sabil) di Yogyakarta tahun 1947-1949. Pengumpulan data berupa Studi Kepustakaan yang dilakukan di beberapa Perpustakaan yaitu, Kampus Universitas PGRI Yogyakara, Pepustakaan Daerah (BPAD), Perpustakaan Gramatama Pustaka, Perpustakaan Sonobudoyo dan Kampus Universitas Muhammadiyah Yogyakarta.

Tahap kedua yaitu Heuristik mencari dan mengumpulkan sumber-sumber yang relevan dan berkaitan dengan masalah yang sedang di teliti antara lain menggunakan sumber tertulis berupa buku-buku, jurnal, serta laporan hasil penelitian. Sumber tersebut diperoleh melalui studi kepustakaan (Pianto, 2016). Tahap kedua adalah Kritik Sumber, kritik sumber merupakan kritik yang dilakukan terhadap sumber-sumber atau data-data yang di temukan. Hal yang di maksud adalah sumbersumber atau data-data yang di peroleh harus di uji keabsahannya yang di lakukan melalui kritik Eksternal dan keabsahaanya tentang masalah kredibilitas melalui kritik Interen (Ayuningtyas, Suharso, \& Sodiq, 2016). Tahap ketiga adalah Interpretasi, yaitu menganalisis dan membandingkan dengan sumber-sumber sejarah yang telah di uji keabsahannya melalui kritik sumber (Swastika \& Sugiyanto, 2020). Tahap terakhih yaitu Histiografi, yaitu suatu rekonstruksi dari masa lalu berdasarkan data yang di peroleholeh peneliti sehingga peneliti dengan mudah dapat menyusun sebuah peristiwa sejarah (Susilo, 2008).

Penelitian ini menggunakan teknik penelitian literatur atau studi pustaka. Literatur atau study pustaka adalah kegiatan yang dilakukan untuk menggumpulkan, mengolah dan merangkum sata-data yang telah di dapatkan dengan menggunakan metode atau teknik tertentu sesuai dengan yang di butuhkan peneliti untuk menjawab suatu permasalahan dalam penelitian study Literatur atau penelitian kepustakaan (Sari \& Asmendri, 2020).

\section{PEMBAHASAN}

Gambaran Umum Yogyakarta Pada Masa Revolusi Fisik di Indonesia

\section{a. Kondisi Yogyakarta Masa Revolusi Fisik}

\section{Kondisi Geografis Yogyakarta}

Kota Yogyakarta secara astronomi terletak di antara $110^{\circ} 23^{\prime} 79^{\prime \prime}-110^{\circ} 28^{\prime} 53^{\prime \prime}$ Bujur Timur dan terletak lebih kurang $7^{\circ} 49^{\prime} 26^{\prime \prime}-7^{\circ} 50^{\prime} 84^{\prime \prime}$ Lintang Selatan. Kota Yogyakarta dilalui oleb garis paralel $8^{\circ} 18^{\prime} 4,93^{\prime \prime}$ Lintang Selatan dan garis meridian $110^{\circ} 51^{\prime} 50$ 87" Bujur Timur, di samping itu juga dilalui oleh tiga buah sungai yakni Sungai Gajah Wong yang mengalir di bagian timur kota, Sungai Code yang mengalir di bagian tengah kota, dan Sungai Winongo yang mengalir di bagian barat kota (Ryadi \& Hamoko, 1993).

\section{Kondisi Sosial Yogyakarta}

Kondisi sosial Yogyakarta pada awal kemerdekaan Indonesia sangat memprihatinkan, ketika Belanda mulai memasuki Yogyakarta dan mulai menyerbu pada tanggal 19 Desember 1948 sehingga membuat masyarakat mengungsi di berbagai wilayah yang berada

HISTORIA: Jurnal Pendidik dan Peneliti Sejarah, p-issn:2620-4789 | e-issn:2615-7993 
di Yogyakarta seperti, Bantul, Imogiri, Kretek, Wonosari, Kulon Progo dan di daerah-daerah Pengunungan. Bahkan banyak masyarakat yang pergi untuk mengungsi tidak membawa perlengkapan yang cukup seperti persediaan makanan, pakaian karna sebagian dari mereka merupakan masyarakat yang kurang mampu (Tashadi, dkk. 1991).

\section{Kondisi Ekonomi Yogyakarta}

Kondisi ekonomi Daerah Istimewa Yogyakarta sangat memprihatinkan. Penduduk Yogyakarta yang padat akibat datangnya pengungsi dari Jakarta membuat banyak orang tidak merasakan nasi yang merupakan bahan makan pokok yang sangat penting selama berbulan-bulan. Sebagai gantinya masyarakat Yogyakarta mengantinya dengan Gogik, Tiwul, Gaplek Atau Jagung (Tashadi, dkk 1991). Blokade ekonomi yang dilakukan oleh pihak Belanda membuat kenaikan hargaharga barang makanan, obat-batan dan sebagainya. Krisis ekonomi di Indonesia mencapai puncaknya ketika Agresi Milite Belanda II terjadi di Yogyakarta (Maegana, Fakih, \& Winardi, 2017).

\section{b. Yogyakarta Masa Revolusi Fisik}

Jatuhnya bom atom di kota Hirosima pada tanggal 6 Agustus 1945 dan di Nagasaki pada tanggal 9 Agustus 1945 ternyata mempercepat proses penyerahan Jepang kepada sekutu. Berita tentang penyerahan Jepang kepada Sekutu ini secara resmi telah di umumkan oleh PM Suzuki tepat setelah sidang kabinet darurat yaitu pada tanggal 15 Agustus 1945 (Tashadi, dkk, 1991). Kekalahan Jepang pada Perang Pasifik membuat Indonesia segera memproklamasikan kemerdekaan. Presiden Ir. Soekarno dengan segera mengumandangkan pidato Proklamasi dan di dampingi oleh wakil Presiden Drs, Moh. Hatta atas nama Bangsa Indonesia pada pukul 10.00 WIB di Jalan Pegangsaan Timur No. 56, Jakarta Pusat (Aprianto \& Yulianto, 2019).

Kedatangan sekutu di berbagai daerah yang berada di Indonesia, membuat situasi di Indonesia semakin sulit. Kekacauan yang dilakukan oleh anggota NICA tersebut sangat meresahkan masyarakat Indonesia, aksi yang dilakukan oleh Nica tersebut tentulah memiliki maksud tertentu yaitu NICA berharap dengan adanya kekacauan tersebut Sekutu akan sangat mudah untuk kembali menguasai Indonesia Setelah berakhirnya masa kedudukan Jepang di Indonesia, maka pada akhir September 1945 datanglah pasukan sekutu yang pada hakekatnya akan mengembalikan kekuasan Belanda. Menurut anggapan mereka Indonesia adalah "milik" Belanda yang direbut oleh Jepang pada waktu Perang Dunia II. Berhubung perang telah selesai dan Jepang kalah, maka Indonesia harus dikembalikan kepada pihak Belanda (Ayuningtyas, Suharso \& Sodiq, 2016).

\section{Agresi Militer Belanda I}

Perundingan antara Indonesia dan Belanda yang di laksanakan di Lingarjati, yaitu di dekat daerah Cirebon dan di Jakarta dengan delegasi dari pihak Indonesia yaitu Sultan Syahrir dan dari pihak Belanda yaitu Prof Schermerhorn pada tanggal 15 November 1946 mengasilkan perjanjian Linggarjati. Namun perjanjian Lingarjati antara Indonesia dengan Belanda tidak mendapatkan kesepakatan dari pihak Belanda (Kansil \& Julianto, 1988). Sehingga Belanda melakukan Aksi militer Belanda I yang di mulai pada tanggal 19 Juli 1947 pukul 17.00 WIB Belanda melancarkan pemboman dan tembakan di lapangan terbang Maguwo dan Belanda kembali menyerang pada sekitar jam 15.00, serangan yang dilakukan tidak hanya di Yogyakarta saja melainkan di berbagai daerah Indonesia lainnya (Tashadi dkk, 1991).

\section{Peristiwa Pemberontakan PKI di Gunungkidul}

Pada bulan Agustus 1948 Musso tokoh kawakan PKI yang tinggal di Moskow telah kembali ke Indonesia, kedatangan Musso ini adalah untuk membawa garis baru bagi kaum komunis pada akhir bulan Agustus 1948 yaitu dengan mengabungkan partai sosialis, partai buruh dan PKI menjadi satu yaitu dengan nama PKI (Bizawie, 2014). Menurut Setiawan (1997), Kabupaten Gunungkidul Daerah Istimewa Yogyakarta merupakan daerah yang di pilihan oleh para pemberontakan PKI untuk melarikan diri dari pasukan TNI serta para pejuang lainnya. Mereka memasuki wilayah Gunungkidul melalui Wonosari dan membuat pertahanan di desa Pojong. Para pemberontakan PKI yang lari ke Gunungkidul berhasil memengaruhi tokoh serta masyarakat di daerah Pojong dan kemudian para pemberontakan PKI mulai melakukan penyerangan di beberapa wilayah yang berada di Gunungkidul.

Pemberotakan PKI di Gunungkidul tidaklah berlangsung lama, hal ini dikarenakan bantuan yang dilakukan oleh polisi, pasukan APS (Askar Perang Sabil) serta dukungan dari masyarakat setempat sehingga pemberontakan PKIdapat dituntaskan, mereka juga dapat dipukul mundur dari Yogyakarta khusunya di wilayah Gunugkidul ke Wonosari melalui desa Manyaran. Setelah penumpasan para anggota PKI, wilayah Gunungkidul juga dilakukan pembersihan terhadap orang-orang yang terlibat oleh aksi pemberontakan PKI. Pembersihan ini dilakukan oleh TNI, polisi, Askar Perang Sabil (APS) dan para pejuang lainnya, hal ini dilakukan agar mereka tidak merugikan Negara Indonesia (Dwiyono, 2012). 
HISTORIA: Jurnal Pendidik dan Peneliti Sejarah, 5(1), 81-88. https://doi.org/10.17509/historia.v5i1.34537

\section{Agresi Militer Belanda II}

Menurut Zainul (2014), setelah pemberontakan PKI di Madiun dan di Yogyakarat khusunya di Gunungkidul telah selesai namun menurut Kansil dan Julianto (1988) konflik yang terjadi antara Indonesia dengan Belanda belum juga usai. Sehingga pada tanggal 6 Desember 1947 dilakukanlah sebuah perundingan yaitu perjanjian Renville. Namun perundingan perjanjian Renville ini mengalami kegagalan. Kegagalan perundingan antar ke dua belah pihak tersebut membuat pihak Belanda pada tanggal 19 Desember 1948 pagi hari mulai melakukan penyerangan lagi setelah menguasai lapangan maguwo pada tanggal 21 Juli 1948. Tindakan Agresi Militer Belanda II telah mengakibatkan reaksi dari dunia terhadap Negara Indonesia semakin besar. Sehingga tercapailah persetujuan Rum-Royen pada tanggal 7 Mei 1949 (Kansil \& Julianto, 1988).

\section{Peristiwa Serangan Umum 1 Maret}

Serangan umum 1 Maret 1949 di Yogyakarta merupakan serangan yang dilakukan oleh gabungan dari berbagai macam kekuatan, baik itu dari Para Tokoh, Ulama, Organisasi, Laskar-Laskar untuk mencapai sebuah tujuan yaitu mempertahankan kemerdekaan Indonesia yang telah diproklamasikan pada tanggal 17 Agustus 1945 (Margana, Ibrahim, \& Nigrum, 2019). Sultan Hamnegku Buwono IX pun menyusun sebuah rencana rahasia bersama Suharto, dibawah komando Soeharto mulai serangan Umum dengan melakukan serangan kecil dulu terhadap pos-pos militer Belanda yang berada di luar kota tujuannya untuk memperdaya pasukan Belanda. Setelah penyerangan kecil dilakukan, pada tanggal 1 Maret 1949 serangan secara besarbesarpun terjadi, sekitar 2000 tentara diturunkan untuk melawan Belanda (Uddin, Harnoko, \& Nurhajarinni, 2020).

Setelah serangan Umum 1 Maret 1949 di Yogyakarta berakhir, Soekarno mendapatkan undangan untuk segera melaksanakan KMB (Konferensi Meja Bundar). maka pada tanggal 23 Agustus 1949 diselenggarakannya KMD di Den Haag dan mendapatkan keputusan besar yaitu persiapan pengakuan kedaulatan Indonesia yang dilakukan sebelum 30 Desember 1949. Maka pada tanggal 27 Desember 1949 proses penyerahan kedaulatan dilaksanakan dengan melakukan upacara simbolik yaitu penurunan Bendera Belanda dan dikibarkannya Bendera Sang Saka Merah Putih sebagai tanda berakhirnya kekuasaan Belanda di Inodonesia (Margana, Ibrahim, \& Nigrum 2019).

\section{Gambaran Umum Ulama Masa Revolusi Fisik di Yogyakarta}

Menurut Fuadi (2014), lahirnya para tokohtokoh islam dan para ulama di Indonesia khususnya di Yogyakarta diwarnai dengan aksi-aksi yang dilakukan oleh para penjajah. Meski demikian para ulama tidak tinggal diam melihat rakyat Indonesia yang menderita akibat tindakan penjajah. Para ulama melakukan berbagai upaya antara lain memberikan pendidikan sebagai alat utama melawan para penjajah. Aksi yang telah di lakukan oleh para penjajah tersebut membuat para ulama seperti NU, Muhammadiyah dan MIAI bersama berjuang mempertahankan kemerdekaan Indonesia khususnya di Yogyakarta. Dengan membentuk sebuah laskar Islam yang bertujuan membantu pata pejuang di medan pertempuran. Selain itu para ulama juga memberikan sebuah landasan Relegius tentang jihad kepada seluruh masyarakat untuk ikut bergabung dalam perjuangan Kemerdekaan Indonesia (Maegana, Fakih, \& Winardi, 2017).

\section{Laskar Hisbullah}

Laskar Hisbullah yang di ketuai oleh $\mathrm{H}$. Wasir Nuri cabang Yogyakarta terbentuk pada tanggal 3 Oktober 1944. Anggota yang tergabung dalam laskar ini berasal dari anggota-anggota organisasi Islam, seperti Muhammadiyah, NU. Orang-orang yang ingin mendaftarkan diri menjadi anggota di Laskar Hisbullah harus melalui serangkaian tes, tes yang dimaksud seperti tes fisik dan tes pengetahuan agama (Maegana, Fakih, \& Winardi, 2017). Secara fungsional pembentukan dari laskar Hisbullah ini adalah untuk membantu para pejuang sebelumnya yaitu PETA dalam mempertahankan serta membela tanah air. Sedangkan secara idiologis pembentukan laskar Hisbullah adalah untuk menjunjung tinggi perintah agama islam, yakni memperjuangkan kemerdekaan di jalan Allah SWT (Bizawie, 2014).

\section{Laskar Sabillilah}

Terbentuknya laskar Hizbullah yang beranggotakan para ulama serta santri-santri di Yogyakarta, maka Masyumi cabang Yogyakarta juga telah membentuk suatu badan perjuangan Kemerdekaan yang diberi nama laskar Sabilillah yang terbentuk di Yogyakarta pada awal tahun 1946. Para ulama yang tergabung dalam Laskar Sabilillah antara lain yaitu: K. H Ahmad Badawi, K.H. Mahfudz, K. H. Amin, H. Djuraimi, K. H. Abdullah, .H.R. Hadjid, K, K.H. Bagus Hadikusumo, K.H. Abdul Aziz, K.H. Djohar, K.H. Daim, K.H. Ahmad Bawawi, Bakri Syahid, M. Sarbini dan Abdullah Mabrur. Ulama mempunyai ilmu agama islam yang kuat sehingga dapat 
meningkatkan semangat para pejuang dalam melawan para penjajah maka tugas para ulama yang tergabung di Laskar Sabilillah adalah di Front belakang yaitu sebagai penasehat. Sedangkan para anggota yang tergabung merupakan para pemuda-pemuda islam (Suratmin, 1997: 18-19).

\section{APS (Askar Perang Sabil)}

APS (Askar Perang Sabil)merupakan laskar islam yang di bentuk oleh para ulama Muhammadiyah Yogyakarta pada saat Agresi Militer Belanda 1 terjadi di Yogyakarta pada tanggal 19 Juli 1947 yaitu pada tanggal 23 Juli 1947. Para anggota APS (Askar Perang Sabil) merupakan bekas dari laskar Hisbullah dan Sabilillah, mereka sangat aktif dalam mempertahankan serta memperjuangkan Indonesia. Kejadian Agresi Militer I contohnya telah membuat APS (Askar Perang Sabil) merasa terpanggil untuk ikut berjuang melawan Belanda (Tashadi, Harnoko, \& Nurdiyanto, 2000).

\section{Peranan Ulama Muhammadiyah Dalam Pembentukan APS (Askar Perang Sabil) di Yogyakarta}

Masa Revolusi Fisik telah membuat para Ulama khususnya ulama Muhammadiyah merasa sangat khawatir atas tindakan Belanda yang melakukan Agresi Militer I dan menyebabkan Belanda menduduki beberapa daerah yang berada di jawa tengah,. Sehingga para ulama menjalankan ibadah Itikaf Bermunajad At-Taqwa pada bulan Ramadhan 1947 dan do'a untuk memohon kepada Allah SWT agar diberikan kekuatan dan keberkahan untuk melawan tentara kolonial di Kampung Suronatan Yogyakarta. Hasil dari Iktikaf itu para ulama atau kyai Muhammadiyah di Yogyakarta sepakat untuk memdirikan sebuah Laskar yang di beri nama yaitu APS (Askar Perang Sabil) MUAPS (Markas Ulama Askar Perang Sabi) sebagai wadah organisasi bagi pemimpinnya (Tashadi, Harnoko, \& Nurdiyanto, 2000).

Terbentuknya APS (Askar Perang Sabil) dan MUAPS (Markas Ulama Askar Perang Sabil) atas gagasan yang telah disampaikan oleh para ulama Muhammadiyah melalui musyawarah yang di lakukan di Yoyakarta dan dihadiri oleh K.H.R. Hadjid, K.H. Juraimi, K.H. Mahfudz Siradj, K.H. Bagus Hadikusumo, K.H. Abdul Aziz, K.H. Djohar, K.H. Amin, K.H. Daim, K.H. Ahmad Bawawi, Ahmad Badawi, Bakri Syahid, M. Sarbini, Abdullah Mabrur (Aprianto \& Yulianto, 2019).

Menurut Suratmin (1997), pembentukan APS (Askar Perang Sabil) mendapatkan restu dari Sri Sultan Hamengku Buwono IX dan Panglima Besar Jenderal Soedirman bahkan Panglima Besar Jenderal Sudirman bersedia untuk memberikan bantuan seperti perlengkapan latihan dan memberikan tenaga kepelatihan kepada APS (Askar Perang Sabil) yang dipimpin oleh Mayor Fakhrudin, bahkan kepada para Tokoh Masyarakat, Pemerintah Sipil, Militer dan Komandan Militer setempat dengan persetujuan dari para tokoh tersebut secara resmi terbentuklah APS (Askar Perang Sabil) dan MUAPS (Markas Ulama Askar Perang Sabil) pada tanggal 23 Juli 1947 bertepatan dengan tanggal 17 Ramadhan $1367 \mathrm{H}$ di yogyakarta (Tashadi, Harnoko, \& Nurdiyanto, 2000).

Pembinaan idiologi Jihad Fii Sabilillah dilakukan oleh para ulama kepada para anggota APS (Askar Perang Sabil) di Pondok Pesantren dan Pengajian-Pengajian yang selalu diselenggarakan di setiap desa-desa di wilayah Yogykarta. Di tempat-tempat seperti inilah para ulama melakukan ceramah serta menanamkan semangat Jihat Fii Sabilillah yaitu semangat dalam memperjuangkan serta mempertahankan kemerdekaan Indonesia dari para penjajah. (Suratmin, 1997).

Semangat idiologi Jihad Fii Sabilillah dalam memperjuangkan kemerdekaan Indonesia atas firman Allah SWT dalam surat An-Nisa' ayat 75. Bahwasannya umat islam dianjurkan untuk ikut berjuang serta melawan para penjajah dan didalam ayat ini selalu diajarkan bahwasannya untuk selalu menegakkan kebenaran serta keadilan sesuai dengan idiologi umat islam. Ideologi Jihad Fi Sabilillah selalu di tanamkan para anggota APS (Askar Perang Sabil) serta kalangan masyarakat untuk dapat menjalani kehidupan yang lebih baik (Tashadi, Harnoko, \& Nurdiyanto, 2000).

Kekuatan Fisik setiap anggota APS (Askar Perang Sabil) merupakan hal yang sangat penting bagi para pejuang untuk menghadapi segala tantangan-tantangan para musuh mereka. Para Anggota APS (Askar Perang Sabil) ini dilatih oleh bekas anggota Hisbullah, selain itu Markas Ulama Askar Perang Sabil (MUAPS) selaku wadah organisasi APS (Askar Perang Sabil) meminta kepada TNI untuk membantu untuk melatih para anggota APS (Askar Perang Sabil). Pelatihan militer ini dipimpin oleh Bung Tomo dan Mayor Fakhruddin. Latihan fisik ini dilkukan di halaman besar Masjid Kauman. Bentuk latihan fisik antara lain dalam menggunakan senjata, latihan baris-berbaris, latihan bergeriliya, latihan berperang serta latihan membela diri (Suratmin, 1997).

Kemampuan yang sangat diperlukan untuk para pejuang seperti APS (Askar Perang Sabil) adalah memiliki pengetahuan islam yang cukup. Maka dari itu sebelum anggota APS (Askar Perang Sabil) di kirim ke medan pertempuran, anggota akan di beri bekal pembinaan kerohanian di samping pelatihan fisik. Para ulama di Markas Ulama Askar Perang Sabil (MUAPS) memiliki peranan penting dalam memberikan 
HISTORIA: Jurnal Pendidik dan Peneliti Sejarah, 5(1), 81-88. https://doi.org/10.17509/historia.v5i1.34537

bimbingan kerohanian agar para anggota APS (Askar Perang Sabil) memiliki pengetahuan tentang islam serta tabah dan iklas untuk berperang demi mempertahankan kemerdekaan Indonesia (Maegana, Fakih, \& Winardi, 2017.

Materi yang diberikan oleh MUAPS (Ulama Askar Perang Sabil) dalam pembinaan kerohanian yaitu pengajaran Tauhhid, Keimanan, Sholat Tahajud serta Do'a-do'a yang mana telah tercantum didalam kitab AlQur'an dan Hadist. Pembinaan kerohanian ini dilakukan di Pesantren, Masjid dan Sekolah, setelah diberikaan pembinaan tentang kerohanian diharapkan para anggota APS (Askar Perang Sabil) dapat mempertebal iman serta kepribadian mereka. Selain itu para MUAPS (Ulama Askar Perang Sabil) juga mengiringi do’a-do’a kepada para anggota APS (Askar Perang Sabil) yang akan diberangkatkan ke medan pertempuran. Dóa yang diberikan oleh para ulama berisikan tentang permohonan kepada Allah SWT agar para anggota APS (Askar Perang Sabil) mendapatkan ketenangan dalam menghadapi tugas-tugas yang sangat berat (Suratmin, 1997).

\section{SIMPULAN}

Pada tanggal 17 Agustus 1945 Indonesia mengumunkan Kemerdekaan. kemerdekaan ini ternyata bukan menjadi akhir dari perjuangan rakyat Indonesia. Masa ini di kenal dengan nama Revolusi Fisik. Masa ini diawali ketika Belanda yang datang kembali ke Indonesia dengan melakukan serangan Agresi Militer Belanda I dan II serta serangan yang datang dari dalam Negri Indonesia sendiri yaitu pemberontakan PKI di madiun khususnya di Yogyakarta serta puncaknya yaitu ketika terjadinya Serangan Umum 1 Maret 1949. Masa Revolusi Fisik di Indonesia khusunya di Yogyakarta telah membuat seluruh masyarakat baik para Pemuda, Wanita bahkan para Ulama ikut berjuang bersama-sama melawan penjajah untuk mencapai suatu kemerdekaan. Para Ulama sangat berperan penting dalam mempertahankan kemerdekaan. dengan menyerukan Fatwa Jihad kepada seluruh umat Islam yang berada di Indonesia untuk ikut berperang melawan para penjajah, yaitu hukuman bagi memerangi orang kafir adalah Fardu A'in dan bagi orang yang meninggal dalam keadaan melawan penjajah adalah mati Syahid. Selain itu para ulama juga membuat laskar-laskar islam yang bernama Hisbullah, Sabililah dan APS (Askar Perang Sabil) untuk membantu para pejuang baik di garis belakang mapun di garis terdepan dalam melawan para kolonial di Indoneisa. Para ulama Muhammadiyah di Yogyakarta juga telah membentuk laskar islam dan telah di setujui oleh Sultan Hamengku Buwono IX, Jendral Sudirman serta para tokoh lainya untuk membantu para pejuang di garis terdepan. Laskar ini bernama APS (Askar Perang Sabil) bersama dengan Markas MUAPS (Ulama Askar Perang Sabil) yang merupakan wadah organisasi bagi pemimpinnya. Laskar ini terbentuk Pada tanggal 23 Juli 1947 atau bertepatan dengan tanggal 17 Ramadhan 1367 H. laskar ini dibentuk oleh para ulama-ulama Muhammadiyah karena kekhwatiran mereka setelah Belanda yang akan datang ke Yogyakarta. para anggota APS (Askar Perang Sabil) ini melakukan beberapa pelatihan seperti pembinaan Idiologi, pembinaan fisik, pembinaan kerohanian. Terbentuknya laskar ini untuk membantu para militer utama yaitu TNI di garis terdepan.

\section{REFERENSI}

Aprianto, I. D., \& Yulianto, A. E. (2019). Askar Perang sabil dalam revolusi fisik di yogyakarta Tahun 19451949. Walasuji, 10(2), 175-184.

Ayuningtyas, D. R., Suharso, R., \& Sodiq, I. (2016). Perjuangan panglima besar jenderal soedirman pada masa revolusi fisik tahun 1945-1950. Journal of Indonesian History, 5(1), 135-144.

Birsyada, M. I. and Syahruzah, J. K. (2018). Social change in yogyakarta: past and now a selo soemardjan perspective. Historia: Jurnal Program Studi Pendidikan Sejarah, 6(1), pp. 103-116. doi: 10.24127/ hj.v6i1.1150.

Bizawie, Z.M. (2014). Laskar ulama-santri dan resolusi jihad garda depan menegakkan indonesia (1945-149). Pustaka Compas.

Dwiyono. E. (2012). Peranan askar perang sabil (aps) dalam operasi penumpasan pemberontakan pki di kabupaten gunungkidul tahun 1948. Skripsi: Fakultas Ilmu Sosial Universitas Negri Yogyakarta.

Kansil C.S.T \& Julianto. (1977). Sejarah perjuangan pergerakan kebangsaan indonesia (pendidikan sejarah perjuangan bangsa). Erlangga.

Maegana, S., Fakih, F., \& Winardi, U, N. (2017). Gelora di tanah raja: yogyakarta pada masa revolusi 1945-1949. Dinas Kebudayaan.

Maftukhin, M. (2016). Islam jawa in diaspora and questions on locality. Journal of Indonesian Islam, 10(2), 375-394.

Margana, S,. Ibrahim, J., \& Nigrum S, U, D. (2019). Serangan umum 1 maret 1949. Dinas Kebudayaan.

Nakamura, M. (2017). Bulan sabitmunculdaribalikpohon beringin studi tentang pergerakan muhammadiyah di kotagede, yogyakarta. Suara Muhammadiyah.

Pianto, H.A. (2016). Pentingnya penulisan sejarah lokal di pacitan tahun 1999-2014. Jurnal Ilmiah LPPM. 2 (2), hal. 61-69. https://jurnal.ustjogja.ac.id/index. php/sosio/article/view/553/247.

HISTORIA: Jurnal Pendidik dan Peneliti Sejarah, p-issn:2620-4789 | e-issn:2615-7993 
Pidada, I.B.A. (2018). Bentuk-bentuk tindakan belanda terhadap pejuang pada masa revolusi fisik di bali. Jurnal Bahasa dan Budaya, 2(1), 9-18. http://dx.doi. org/10.22225/kulturistik.2.1.447.

Ryadi, G., \& Hamoko. (1985). Sejarah sosial daerah istimewa yogyakarta mobilitas sosial d.i yogyakarta periode awal abad xxan. Depertemen Pendidikan Dan Kebudayaan Direktorat Sejarah dan Nilai Tradisional Proyek Investasi dan Dokumentasi Sejarah Nasional.

Sari, M., \& Asmendri, A. (2020). Penelitian kepustakaan (library research) dalam penelitian pendidikan IPA. Natural Science: Jurnal Penelitian Bidang IPA Dan Pendidikan IPA, 6(1), 41-53. https://ejournal. uinib.ac.id/jurnal/index.php/naturalscience/article/ view/1555

Setiawati, N. A. (2018). Manajemen Sejarah Berbasis Komunitas: Pengembangan Kawasan Kauman sebagai Living Museum. Bakti Budaya: Jurnal Pengabdian kepada Masyarakat, 1(1), 101-121. https://journal. ugm.ac.id/bakti/article/view/37934.

Suratmin. (1997). Askar perang sabil sebagai kekuatan sosio relegius dalam masa revolusi fisik di daerah istimewa yogyakarta 1945-1949. Departemen Pendidikan dan Kebudayaan Direktorat Jendral Kebudayaan Direktorat Sejarah dan Nilai Tradisional Balai Kajian Sejarah dan Nilai Tradisional Yogyakarta.

Susilo, A. (2018). Sejarah perjuangan jenderal soedirman dalam mempertahankan indonesia (1945-1950). HISTORIA: Jurnal Program Studi Pendidikan Sejarah, 6(1), 57-68.
Sutarto, S., Sari, D. P., \& Anrial, A. (2020). Kiprah muhammadiyah dalam pembaharuan pendidikan dan sosial keagamaan di nusantara: kajian terhadap pemikiran kh. ahmad dahlan. Belajea: Jurnal Pendidikan Islam, 5(1), 1-22. http://journal. staincurup.ac.id/indek.php/belajea.

Tashadi dkk. (1991). Sejarah revolusi kemerdekaan 19451949 di daerah istimewa yogyakarta. Depdikbud.

Tashadi, Harnoko, D., \& Nurdiyanto. (2000). Keterlibatan ulama di diy pada masa perang kemerdekaan periode 1945-1949. Putra Prima.

Uddin, B., Harnoko, D, \& Nurhajarinni D, R. (2020). Masyarakat pedesaan dan revolusi kemerdekaan di daerah istimewa yogyakarta. Dinas Kebudayaan Daerah Istimewa Yogyakarta.

Wasnio. (2007). Dari riset hingga tulisan sejarah. Panitia Pengadaan Buku Ajar Guggus Pengembangan Mutu Akademik Pusat Penjamin Mutu Universitas Negri Semarang Dan Penerbit Unnes Press.

Woodward, M. (1989). Islam in java: normative piety and mysticism in the sultanate of yogyakarta. in islam in java: normative piety and mysticism in the sultanate of yogyakarta. University of Arizona Press, Tucson; Association for Asian Studies Monograph, 45.

Yanti, R. D. (2020). Potret Gerakan Perempuan pada Abad Ke 20 di Batavia: Poetri Mardika 1912. Historia: Jurnal Pendidik dan Peneliti Sejarah, 3(2), 135-144. https://doi.org/10.17509/historia.v3i2.23001.

Zainal, F., Swastika, K., \& Sugiyanto. (2020). The Dynamics of indonesia lumajang football club in 1947-2018. Jurnal Historica. 4(1), hal. 76-86. https:// jurnal.unej.ac.id/index.php/JHIS/article/view/16375. 